\title{
Propylthiouracil Treatment Decreases the Susceptibility to Oxygen Radical-Induced Lung Damage in Newborn Rats Exposed to Prolonged Hyperoxia
}

\author{
MARIA RODRIGUEZ-PIERCE, ILENE R. S. SOSENKO, PHILIP WHITNEY, AND LEE FRANK \\ Department of Pediatrics, Division of Neonatology: and Department of Medicine, Pulmonary Research Center, \\ University of Miami School of Medicine, Miami, Florida 33136
}

\begin{abstract}
In newborn rats, antenatal thyroid stimulation with thyroid-releasing hormone is associated with developmental decreases in pulmonary antioxidant enzyme activities and decreased survival rates during prolonged hyperoxic exposure, with pathologic evidence of increased $\mathrm{O}_{2}$-induced lung damage. Propylthiouracil (PTU), in addition to its antithyroid effects, reportedly has antioxidant properties. To explore possible pulmonary protective effects from both the antithyroid and antioxidant properties of PTU, we administered PTU (0.015\%) in drinking water to timed-pregnant rats for the final $10 \mathrm{~d}$ of gestation and during lactation; control rats received untreated water. The survival rate of the PTU-treated pups when placed in more than $95 \% \mathrm{O}_{2}$ at birth was consistently higher at all time periods in hyperoxia from 6 d [PTU, 81 of $81(100 \%)$ control pups, 70 of $84(83 \%) ; p<0.01]$ to $14 \mathrm{~d}$ [P'TU, 41 of $53(77 \%)$; control pups $=14$ of $56(25 \%) ; p<0.01$. Further evidence of increased tolerance to more than $95 \%$ $\mathrm{O}_{2}$ in PTU pups included a significant decrease in the incidence of microscopic intraalveolar edema, decreased lipid peroxidation (malondialdehyde), and a significant increase in lung tissue surfactant-related phospholipids compared with $\mathrm{O}_{2}$-exposed control pups. No differences were present in lung structural maturation, antioxidant enzyme activity response to hyperoxia, or lung tissue $\mathrm{O}_{2}$ radical formation in more than $95 \% \mathrm{O}_{2}$. We conclude that PTU treatment has important postnatal effects that protect newborn rats against oxidant-induced lung injury and lethality during hyperoxia, which may be related to PTU inhibition of thyroid hormone production, effect on $\mathrm{O}_{2}$ metabolism, or its direct antioxidant properties. (Pediatr Res 35: 530535,1994 )
\end{abstract}

\section{Abbreviations}

TRH, thyrotropin-releasing hormone

$T_{3}, 3,3$ ',5-triiodo-L-thyronine

$T_{4}$, thyroxine

AOE, antioxidant enzyme

DSPC, disaturated phosphatidylcholine

TPL, total phospholipid

$\mathrm{Lm}$, mean linear intercept (mean air space diameter)

ISA, internal surface area

PTU, propylthiouracil

MDA, malondialdehyde

Received March 24, 1993; accepted December 13, 1993

Correspondence and reprint requests: Maria Rodriguez-Pierce, M.D., Department of Pediatrics, Section of Neonatology, Tulane Medical Center, 1430 Tulane Ave., New Orleans, LA 70112.
Increased production of highly reactive $\mathrm{O}_{2}$ free radicals has been postulated as a major factor in the development of lung injury during hyperoxic exposure (1). Cell survival under hyperoxic conditions requires that the cell has the capacity to respond to this oxidative stress with an increase in the activity of those defense systems that can detoxify reactive species of $\mathrm{O}_{2}$ and thereby prevent $\mathrm{O}_{2}$ toxicity.

Our laboratory has previously demonstrated that fetal thyroid hormone stimulation with the prenatal administration of $\mathrm{T}_{3}$ or TRH to pregnant rats in late gestation produced lower baseline lung AOE activity levels in their offspring $(2,3)$. TRH-treated pups demonstrated decreased newborn survival rates during prolonged hyperoxic exposure with evidence of increased lipid peroxidation and intraalveolar edema, all reflective of greater susceptibility to $\mathrm{O}_{2}$ radical-induced lung damage (4).

PTU is a thioamide derivative that inhibits thyroid hormone synthesis (5). In addition, PTU has recently been reported to be an $\mathrm{O}_{2}$ radical scavenger and an efficient inhibitor of lipid peroxidation (6). It is currently being used successfully to treat alcoholic liver disease (7) in which chronic ethanol administration has been shown to induce a hepatic hypermetabolic state with increases in hepatic $\mathrm{O}_{2}$ consumption and $\mathrm{O}_{2}$ radical production (8).

To explore possible pulmonary protective effects from both the antithyroid and antioxidant properties of PTU, we undertook a series of experimental studies examining hyperoxic survival plus a number of parameters of pulmonary $\mathrm{O}_{2}$ toxicity in the rapidly growing lungs of newborn animals. On the basis of the previous $T_{3}$ and TRH studies, we hypothesized that newborn rats treated with PTU would demonstrate superior tolerance to prolonged high $\mathrm{O}_{2}$ exposure and an associated decreased susceptibility to $\mathrm{O}_{2}$ radical-induced lung injury.

\section{MATERIALS AND METHODS}

Animals and treatment. Sprague-Dawley albino rats originally obtained from Charles River Laboratories (Wilmington, MA) and maintained in the animal care facilities of the University of Miami School of Medicine under veterinary supervision were used. Breeding was accomplished by placing male and female animals together overnight, checking for sperm-positive vaginal smears the following morning, and considering the midpoint of the cohabitation period as the onset of pregnancy. The timedpregnant rats were maintained on water and standard rat pellet diet (Rodent Laboratory Chow, Ralston Purina Co., St. Louis, MO) ad libitum and kept on a 12-h light/dark cycle.

Ten days before expected delivery of full-term (d 22 of gestation) offspring, pregnant dams were randomly assigned to either a control group or a PTU treatment group. PTU (Sigma Chemical Co., St Louis, MO), $0.015 \%$, was administered in the drink- 
ing water, which was made up fresh daily. The control group received drinking water not treated with PTU. With little variability, both PTU and control dams consumed approximately 60 $\mathrm{mL}$ water per day. This amount calculates to a dose of $\sim 30 \mathrm{mg} /$ $\mathrm{kg} / \mathrm{d}$ (approximately twice the directly administered clinical dosage). This regimen has been used previously by others and has been shown to be effective in inhibiting thyroid hormone synthesis without influencing litter size or viability (9).

Newborn rats were obtained by normal parturition within $6-$ $12 \mathrm{~h}$ of the beginning of delivery of the first pup. The newborn pups from several equivalently treated litters (PTU or control) were first pooled and then randomly redistributed to the equivalently treated newly delivered dams. Dams plus 10-12 pups/ litter were randomly assigned to either a hyperoxic exposure $\left(>95 \% \mathrm{O}_{2}\right)$ or room air exposure group.

Exposures to hyperoxia $(96-98 \%)$ were conducted in 3.5 cubic-foot clear plastic exposure chambers adapted from regular infant isolettes (model 86; Air Shiclds, Hatboro, PA) as previously reported (4). The chambers were opened daily (10-15 min) to provide fresh food, water, and cages; to weigh the rat litters; and to interchange mothers between litters exposed to $\mathrm{O}_{2}$ and to room air to avoid $\mathrm{O}_{2}$ toxicity in the nursing dams. The offspring were either maintained in hyperoxia for $14 \mathrm{~d}$ for survival studies or killed with an overdose of pentobarbital after 5 or $10 \mathrm{~d}$ of either hyperoxia $\left(>95 \% \mathrm{O}_{2}\right)$ or room air exposure for the lung analyses described below. The total experimental protocol was preapproved by the University of Miami Animal Welfare Committee.

Lung analy'ses. Lung lipid peroxidation was assayed by MDA determination according to the method of Buege and Aust (10), after $5 \mathrm{~d}$ of more than $95 \% \mathrm{O}_{2}$ exposure. Pups were given an overdose of intraperitoneal pentobarbital, and when no response to a toe pinch could be elicited, a midline abdominal incision was made, the aorta was severed to exsanguinate the animal, and the chest cavity was opened in the midline. The right middle lobe was tied off, and the remainder of the lung was rapidly perfused with ice-cold $50 \mathrm{mM}$ Tris- $\mathrm{HCl}$ buffer, pH 7.6 (Sigma) via the pulmonary artery after removing the left atrial appendage to facilitate draining. The right middle lobe was then removed, blotted dry, and placed in a weighed dish for wet/dry measurements. The remainder of the dissected lungs was weighed and homogenized (Brinkmann Polytron Homogenizer, Brinkmann, Westbury, NY) in the Tris-HCl buffer $(10: 1 ; \mathrm{vol} / \mathrm{wt})$ with $0.01 \%$ of butylated hydroxytoluene. Duplicate aliquots were taken from the homogenate. One sample (unincubated) was placed on ice. We added $50 \mu \mathrm{L}$ of $2 \mathrm{M}$ ascorbic acid and $50 \mu \mathrm{L}$ of $0.08 \mathrm{M}$ ferrous sulfate heptahydrate to the samples (incubated), which were then incubated at $37^{\circ} \mathrm{C}$ for $30 \mathrm{~min}$. To both the unincubated and incubated samples, $0.9 \mathrm{~mL}$ of water and $0.6 \mathrm{~mL}$ of trichloroacetic acid $(28 \%)$ were added, and the samples were centrifuged $(5000 \mathrm{rpm} \times 15 \mathrm{~min})$ in a refrigerated centrifuge at $2^{\circ} \mathrm{C}$. We added $230 \mu \mathrm{L}$ of $1 \%$ thiobarbituric acid solution to $1600 \mu \mathrm{L}$ of both supernatants, which were then incubated at $100^{\circ} \mathrm{C}$ for 15 min. A standard assay curve was generated with MDA tetramethyl acetic acid (Eastman Kodak Co., Rochester, NY), and MDA activity was determined spectrophotometrically at $532 \mathrm{~nm}$ as the difference between incubated and unincubated samples and the results expressed as nM MDA/dry lung weight. This method for assessing in vivo lipid peroxidation is known to have shortcomings in complex biologic systems [including the crossreactivity of thiobarbituric acid with different commonly occurring cytosolic compounds (11)]. Nonetheless, it provides a generally acceptable and frequently used indirect means for assessing comparative hyperoxia-related lung damage.

Oxygen radical production was indirectly determined by the rate of cyanide-resistant $\mathrm{O}_{2}$ consumption with the method of Freeman "t al. (12), with minor variations. Rat lungs were perfused in situ with $10 \mathrm{mM}$ potassium phosphate buffer, $\mathrm{pH}$ 7.4 , and homogenized in $50 \mathrm{mM}$ potassium phosphate buffer (15:1; vol/wt) for $30 \mathrm{~s}$ at full speed with an Omni 2000 homogenizer (with a 10-mm probe; Omni International, Inc., Waterbury, CT). After duplicate portions were removed for DNA analysis, the samples were centrifuged at $600 \times g$ for $10 \mathrm{~min}$ to remove nuclei, cells, and connective tissue debris. The supernatant fluid was then used to measure $\mathrm{O}_{2}$ consumption. To $1.5 \mathrm{~mL}$ of sample, $1.5 \mathrm{~mL} 50 \mathrm{mM}$ potassium phosphate buffer and 30 $\mu \mathrm{L}$ of $1 \mathrm{mM}$ NADH were added, and the mixture was then equilibrated with air at $30^{\circ} \mathrm{C}$. The rate of $\mathrm{O}_{2}$ consumption was measured with a YSI model 5300 oxygen monitor equipped with standard bath and electrodes (Yellow Springs Instrument Company, Inc., Yellow Springs, $\mathrm{OH}$ ) and a flatbed recorder. The electrode was then removed, $30 \mu \mathrm{L}$ of $100 \mathrm{mM} \mathrm{NaCN}$ added, the mixture reequilibrated with air, and the rate of cyanideresistant $\mathrm{O}_{2}$ uptake measured. The rate of $\mathrm{O}_{2}$ uptake was expressed as nmol $\mathrm{O}_{2}$ consumed per min per mg DNA. Addition of cyanide caused a 2- to 2.5-fold reduction in the rate of $\mathrm{O}_{2}$ consumption.

For lung AOE activity analysis after $5 \mathrm{~d}$ of more than $95 \% \mathrm{O}_{2}$ or room air exposure, newborn pups from each group were killed as described above, and their lungs were immediately perfused in situ with ice-cold saline and then homogenized in cold saline $(20-30: 1 ; \mathrm{vol} / \mathrm{wt})$. Two to three lungs were pooled per sample to provide adequate lung tissue for the assays. The homogenates were frozen at $-70^{\circ} \mathrm{C}$ for subsequent $\mathrm{AOE}$ analyses. Lung activities of total superoxide dismutase (13), catalase (14), and glutathione peroxidase (15) were assayed by standard spectrophotometric techniques. Purified enzyme standards (superoxide dismutase and catalase) were obtained from Sigma Chemical; glutathione peroxidase standard was obtained from BochringerMannheim Co. (Indianapolis, IN). Lung protein was determined with purified bovine albumin (Sigma) as standard (16), and lung DNA was determined with purified calf thymus DNA (Sigma) as standard (17).

For phospholipid determinations, aliquots of the salineperfused lung homogenates were subjected to lipid extraction according to the procedure of Bligh and Dyer (18). The lipid extract, once dried under nitrogen, was frozen at $-70^{\circ} \mathrm{C}$ before phospholipid analysis. An aliquot of lipid extract was designated for measurement of TPL (19). A second aliquot was used for quantitating DSPC, using the method of Mason et al. (20). After separation of the DSPC from the other phospholipids, both the DSPC sample and the TPL sample were analyzed for inorganic phosphorus as described by Morrison (19). A known quantity of ${ }^{14} \mathrm{C}$-dipalmitoyl-phosphatidylcholine (New England Nuclear,

Table 1. Comparative parame'ters in PTU and control rat offspring after 5 d in $>95 \%$ on or room air*

\begin{tabular}{ccccccc}
\hline Treatment group & \multicolumn{1}{c}{$\begin{array}{c}\text { Body wt } \\
(\mathrm{g})\end{array}$} & $\begin{array}{c}\text { Lung wt } \\
(\mathrm{g})\end{array}$ & $\begin{array}{c}\text { Lung wt/body wt } \\
(\%)\end{array}$ & $\begin{array}{c}\text { Protein } \\
(\mathrm{mg} / \mathrm{g} \text { lung) }\end{array}$ & $\begin{array}{c}\text { DNA } \\
\text { (mg/g lung) }\end{array}$ & Protein/DNA \\
\hline Air control & $12.20 \pm 1.85$ & $0.239 \pm 0.045$ & $1.81 \pm 0.20$ & $68.40 \pm 12.37$ & $9.38 \pm 2.24$ & $7.48 \pm 1.33$ \\
Air PTU & $10.76 \pm 1.12 \dagger$ & $0.185 \pm 0.026 \dagger$ & $1.70 \pm 0.15$ & $62.31 \pm 11.20$ & $8.58 \pm 2.07$ & $7.65 \pm 1.78$ \\
$\mathrm{O}_{2}$ control & $12.13 \pm 1.55$ & $0.218 \pm 0.039$ & $1.75 \pm 0.28$ & $69.05 \pm 12.56$ & $6.92 \pm 2.42 \$$ & $11.45 \pm 2.46 \$$ \\
$\mathrm{O}_{2}$ PTU & $10.26 \pm 1.14 \ddagger$ & $0.151 \pm 0.016 \ddagger$ & $1.42 \pm 0.13 \ddagger$ & $61.00 \pm 13.83$ & $7.84 \pm 2.56$ & $7.65 \pm 1.78 \ddagger$ \\
\hline
\end{tabular}

* Values are means \pm 1 SD for four to nine litters per group.

+ Statistically significant with $p<0.05$ for air PTU wa air control.

$\ddagger$ Statistically significant with $p<0.05$ for $\mathrm{O}_{2} \mathrm{PTU}$ is $\mathrm{O}_{2}$ control.

$\S$ Statistically significant with $p<0.05$ for $\mathrm{O}_{2}$ control is air control. 
Table 2. Serum $T_{3}$ and $T_{4}$ levels in PTU-treated and control offspring after $10 \mathrm{~d}$ in $>95 \% \mathrm{O}_{2}$ or room air*

\begin{tabular}{ccc}
\hline Treatment group & $\mathrm{T}_{3}$ & $\mathrm{~T}_{4}$ \\
$(\mathrm{nmol} / \mathrm{L})$ & $(\mathrm{nmol} / \mathrm{L})$ \\
\hline Air control & $0.447 \pm 0.201$ & $17.23 \pm 5.35$ \\
Air PTU & $<0.138 \dagger$ & $<10.1 \dagger$ \\
$\mathrm{O}_{2}$ control & $0.503 \pm 0.168$ & $17.92 \pm 6.80$ \\
$\mathrm{O}_{2}$ PTU & $<0.138 \dagger$ & $<10.1 \dagger$ \\
\hline
\end{tabular}

* Values are means \pm 1 SD for three litters, five to eight samples per group (assay lower limits $=0.138 \mathrm{nmol} / \mathrm{L}$ for $T_{3}$ and 10.1 for $T_{4}$ ).

+ Statistically significant with $p<0.05$ for all PTU-treated is all control groups.

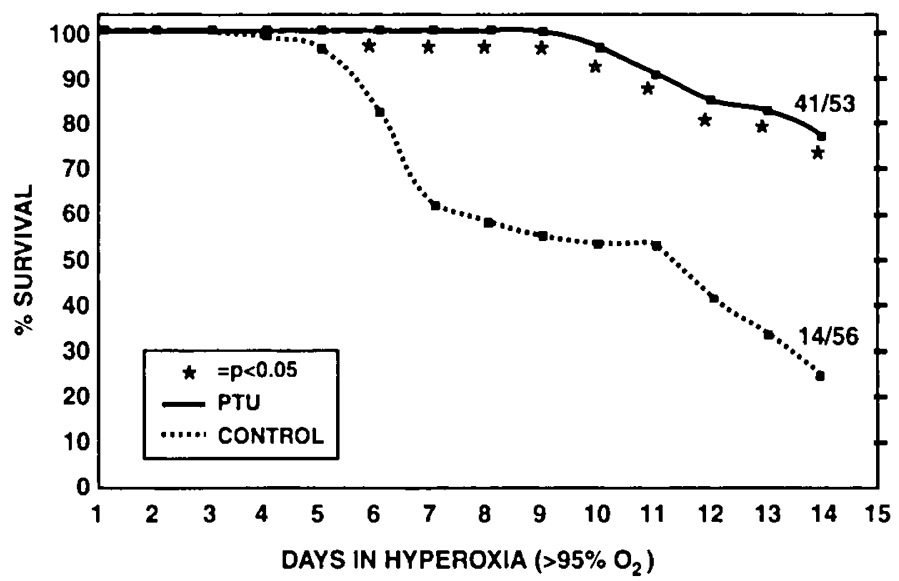

Fig. 1. Survival of PTU-treated and control newborns in $>95 \% \mathrm{O}_{2}$ for $14 \mathrm{~d}\left(n / n=\right.$ number alive/number put in $\left.\mathrm{O}_{2}\right)$. The PTU-treated pup survival rate is significantly increased compared with $\mathrm{O}_{2}$ controls at all time periods from 6 to $14 \mathrm{~d}$ in hyperoxia. ${ }^{*}, p<0.01, \chi^{2}$.
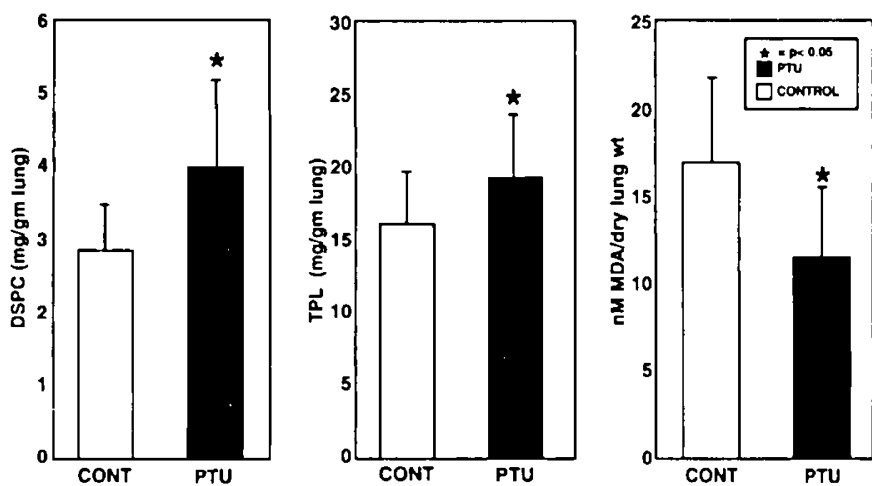

Fig. 2. Lung tissue DSPC, TPL, and MDA content in PTU and control (CONT) rat offspring in $>95 \% \mathrm{O}_{2}$ for $5 \mathrm{~d}$. Values are mean \pm 1 SD for three to five litters per group, eight to 19 samples per group. The air control ' 's air PTU values for DSPC. TPL, and MDA are, respectively, $3.28 \pm 0.63$ vs $3.35 \pm 0.64 \mathrm{mg} / \mathrm{g}$ lung, $18.58 \pm 3.34$ is $18.07 \pm 3.51 \mathrm{mg} /$ g lung, and $12.28 \pm 5.39$ vs $7.39 \pm 1.56 \mathrm{nM} \mathrm{MDA} / \mathrm{g}$ dry lung weight. *, $\mathrm{p}<0.05$ for PTU compared with control group.

Boston, MA) was added before lipid extraction, and aliquots were counted at each step to correct for sequential losses. Lipids were expressed as $\mathrm{mg}$ per g lung wet weight (and also calculated per $\mathrm{mg}$ of protein and as a ratio of $\mathrm{mg}$ DSPC to $\mathrm{mg}$ TPL).

Microscopic studies. For microscopic studies, the pups from each group that had been killed had their lungs inflated in situ through a tracheal catheter at a constant $20 \mathrm{~cm} \mathrm{H_{2 }} \mathrm{O}$ pressure (fixative: $10 \%$ buffered formalin). Fixation was continued in formalin at room temperature for $48 \mathrm{~h}$ before determination of lung volume by water displacement $(21)$ and sectioning. From all lungs, similarly oriented sections from similar portions of the left lung and the right middle and lower lobes were stained with
Table 3. Comparative pulmonary antioxidant enzlme activities in PTU and control rat offspring after $5 \mathrm{~d}$ in $>95 \% \mathrm{O}_{2}$ or room air*

\begin{tabular}{lcll}
\hline Treatment group & \multicolumn{1}{c}{ SOD } & \multicolumn{1}{c}{ CAT } & \multicolumn{1}{c}{ GP } \\
\hline Air control & $78.8 \pm 26.4$ & $309 \pm 85$ & $0.293 \pm 0.038$ \\
Air PTU & $92.3 \pm 16.0$ & $303 \pm 70$ & $0.334 \pm 0.045$ \\
$\mathrm{O}_{2}$ control & $110.0 \pm 26.0 \dagger$ & $403 \pm 132 \dagger$ & $0.501 \pm 0.083 \dagger$ \\
$\mathrm{O}_{2}$ PTU & $108.1 \pm 22.7$ & $389 \pm 95 \dagger$ & $0.538 \pm 0.086 \dagger$ \\
\hline
\end{tabular}

* Values are means \pm 1 SD for four litters, 14 to 15 samples per group. Antioxidant enzymes: superoxide dismutase (SOD), catalase (CAT), and glutathione peroxidase (GP) are expressed as activity units/mg DNA.

$\dagger$ Statistically significant with $p<0.05$ for respective $\mathrm{O}_{2}$-exposed $v$ air-exposed groups.

hematoxylin and eosin and initially examined to eliminate any section with evidence of inadequate preparation (atelectasis). No correction was made for tissue shrinkage. Light level morphometric assessment was performed on coded slides for comparison of lung structural development (alveolarization) in air and $\mathrm{O}_{2-}$ exposed neonatal animals from all experimental groups. We determined $\mathrm{Lm}$, percentage air space/percentage tissue space, ISA, and specific ISA (ISA $/ 100 \mathrm{~g}$ body weight) with a standard integrating eyepiece with seven horizontal lines and 42 intercept bars (Zeiss Optical, Oberkochen, Germany). The coded slides were examined at $\times 400$ magnification by two investigators, with 30 random fields counted per slide. We counted the number of times the intercept bars fell on lung tissue septa per field and the number of transections of airspace walls with the seven horizontal lines per field. To calculate $\mathrm{Lm}$ (representing the average distance between air space walls, or mean air space diameter), we used the following formula: $\mathrm{Lm}=$ (length of line $\times$ number of lines counted $\times$ number of fields)/total number of tissue transections, where the length of each line $=0.20 \mathrm{~mm}$, number of lines $=7$, and number of fields $=30(22)$.

ISA, representing the internal surface area of the lung available for respiratory exchange, was calculated with the formula: ISA $=(4 \times$ lung volume $) / \mathrm{Lm}$, where lung volume is the determined postfixation lung volume (23). Percentage air space was calculated as: $\%$ air space $=\mathrm{Pa} /(\mathrm{Pa}+\mathrm{Pt}) \times 100$, where $\mathrm{Pa}$ is the total number of intercept bars hitting air and $\mathrm{Pt}$ is the total number of intercept bars hitting tissue.

Pulmonary edema was microscopically assessed in coded lung sections by evidence of interstitial or peribronchial-perivascular swelling and pink-staining (proteinaceous) material within the air spaces (intraalveolar edema). Pulmonary edema was also assessed by comparative wet/dry lung weights using nonperfused lung lobes weighed before and after drying in an $80^{\circ} \mathrm{C}$ oven for 48-72 h to reach constant weight.

Serum hormone assay. From randomly selected PTU-treated and control 10-d-old offspring, hormone assays for serum $\mathrm{T}_{3}$ and $\mathrm{T}_{4}$ were performed with specific RIA kits (Incstar Corporation, Stillwater, $M N$ ). The assay sensitivities for $T_{3}$ and $T_{4}$ were 0.138 $\mathrm{nmol} / \mathrm{L}$ and $\leq 10.1 \mathrm{nmol} / \mathrm{L}$, respectively.

Statistical analysis. Survival rates of the treated versus untreated rat pups and assessment of intraalveolar edema were compared by $\chi^{2}$ testing (24). For comparing biochemical values for the two hyperoxic groups with those of the two air control groups, one-way analysis of variance was performed, followed by Duncan's multiple range test (24). For all statistical tests, a $p<$ 0.05 value was considered to represent a significant difference between the compared values.

\section{RESULTS}

Physical characteristics. The influence of prenatal PTU on body weight was determined at birth, and postnatal PTU influence was determined after $5 \mathrm{~d}$ in air or hyperoxia. Body weights were slightly $(-5 \%)$ but significantly decreased at birth in the PTU-treated offspring $(6.31 \pm 0.41)$ compared with the control 
Table 4. Comparative morphometry of newborn rat pup lungs after $10 \mathrm{~d}$ in $>95 \% \mathrm{O}_{2}$ or room air*

\begin{tabular}{ccccc}
\hline Treatment group & $\begin{array}{c}\text { Lung } \\
\text { volume } / 100 \mathrm{~g}\end{array}$ & $\begin{array}{c}\text { Airspace } \\
(\%)\end{array}$ & Lm $(\mu \mathrm{m})$ & ISA $\left(\mathrm{cm}^{2}\right) / 100 \mathrm{~g}$ \\
\hline Air control & $4.08 \pm 0.38$ & $71.4 \pm 3.5$ & $46.7 \pm 2.9$ & $3506 \pm 429$ \\
Air PTU & $3.94 \pm 0.45$ & $74.8 \pm 1.8$ & $51.0 \pm 2.6$ & $3103 \pm 357$ \\
$\mathrm{O}_{2}$ control & $4.36 \pm 0.34$ & $79.2 \pm 2.1 \dagger$ & $72.8 \pm 10.7 \dagger$ & $2465 \pm 279 \dagger$ \\
$\mathrm{O}_{2}$ PTU & $3.76 \pm 0.62$ & $78.1 \pm 3.7$ & $73.9 \pm 5.9 \dagger$ & $2024 \pm 194 \dagger$ \\
\hline
\end{tabular}

* Values are mean $\pm 1 \mathrm{SD}$ for four to six rat lungs per group.

† Statistically significant with $p<0.05$ for respective $\mathrm{O}_{2}$-exposed group $v$ air-exposed group.

offspring $(6.63 \pm 0.62)(p<0.05)$ and remained significantly decreased after $5 \mathrm{~d}$ in air $(-12 \%)$ or in hyperoxia $(-15 \%)$ (Table 1). Lung wet weights were also significantly decreased after $5 \mathrm{~d}$ in air or hyperoxia in the PTU-treated offspring, as were the lung weight/body weight ratios in hyperoxia (Table 1).

PTU treatment followed by $5 \mathrm{~d}$ in air or hyperoxia did not result in significant changes in the normal rate of increase of lung protein or DNA content associated with the maturation process. The greater protein/DNA ratio in the $\mathrm{O}_{2}$ control group (Table 2) largely reflects a significant degree of DNA inhibition in the $\mathrm{O}_{2}$ control group lungs $(-26 \%$ versus respective air control), which was not seen in the $\mathrm{O}_{2}$ PTU group lungs $\mathrm{O}_{2}(-8 \%$ versus respective air PTU).

Survival data. The offspring treated with PTU demonstrated a significantly superior survival rate compared with the control offspring from the 6th d onward in hyperoxia, with the comparative 14-d-survival rate being 3 times greater $(77 \%)$ for the $\mathrm{O}_{2}$ PTU group versus the $\mathrm{O}_{2}$ control group (25\%) (Fig. 1).

Serum hormone assal's. The $\mathrm{T}_{3}$ and $\mathrm{T}_{4}$ serum levels in PTUtreated versus control offspring after $10 \mathrm{~d}$ of either room air or hyperoxic exposure are listed in Table 2. PTU consistently inhibited $\mathrm{T}_{3}$ and $\mathrm{T}_{4}$ levels.

Lung analyses. The lung tissue surfactant-related phospholipids (DSPC and TPL) and MDA content in PTU and control rat offspring after $5 \mathrm{~d}$ of hyperoxia are illustrated in Figure 2 (values for 5-d air-breathing controls with and without PTU are provided in the legend). Offspring of PTU-treated dams had significant increases in lung tissue DSPC and TPL compared with control offspring in hyperoxia and a significant decrease in MDA per dry lung weight, reflecting an inhibition of in vivo lipid peroxidation.

Comparative pulmonary AOE activity responses after $5 \mathrm{~d}$ of hyperoxia were essentially similar between the $\mathrm{O}_{2}$-PTU versus $\mathrm{O}_{2}$-control groups (Table 3). Likewise, measurements of total $\mathrm{O}_{2}$ consumption or cyanide anion-resistant $\mathrm{O}_{2}$ consumption as a reflection of $\mathrm{O}_{2}$ radical production were not different between the PTU $\left(4.0 \pm 0.4 \mathrm{nmol} \mathrm{O}_{2}\right.$ consumed $\left./ \mathrm{min} / \mathrm{mg} \mathrm{DNA}\right)$ and control $\left(4.3 \pm 0.3 \mathrm{nmol} \mathrm{O}_{2}\right.$ consumed $\left./ \mathrm{min} / \mathrm{mg} \mathrm{DNA}\right) \mathrm{O}_{2}$-exposed groups.

Microscopic studies. The comparative lung morphometric findings for PTU-treated and control offspring after $10 \mathrm{~d}$ of hyperoxia are shown in Table 4 . The improved survival in hyperoxia of PTU offspring occurred despite no apparent effect on the magnitude of $\mathrm{O}_{2}$-induced inhibition of normal lung structural maturation associated with hyperoxic exposure. The $\mathrm{Lm}$ values were increased similarly $(\sim 50 \%)$ in both $\mathrm{O}_{2}$ groups, and comparable decreases $(\sim 30 \%)$ were observed in normal ISA development in hyperoxia. Quantitative morphometric studies were also carried out on offspring after $5 \mathrm{~d}$ of hyperoxia with no significant differences between PTU and control offspring (data not shown).

Qualitative examination of the same coded slides used for quantitative morphometry revealed that all the $\mathrm{O}_{2}$-exposed pups had evidence of perivascular or peribronchiolar edema present after 5 and $10 \mathrm{~d}$ of hyperoxic exposure. This microscopic finding was further substantiated by the increased wet/dry lung weights of the $\mathrm{O}_{2}$-exposed offspring versus the offspring maintained in room air. After $5 \mathrm{~d}$ in hyperoxia, no differences were observed in wet/dry lung weights between the PTU $(6.10 \pm 0.59)$ and control $(6.16 \pm 0.79)$ offspring (average air control $=5.37 \pm$ 0.23 ). However, when pathologic evidence of more advanced $\mathrm{O}_{2}$ toxicity was examined, intraalveolar edema was present in $47 \%$ (14 of 30) of the control group lung sections after $5 \mathrm{~d}$ of hyperoxia versus only $7 \%$ (2 of 30$)$ of the PTU group lung sections $(p<$ 0.01 ). By $10 \mathrm{~d}$ in hyperoxia, $14 \%$ (3 of 21 ) of the PTU group lung sections had evidence of intraalveolar edema fluid compared with $59 \%$ (10 of 17) of the control group lung sections $(p<$ $0.01)$. The similar increases in wet/dry weights in the $\mathrm{O}_{2}$ groups suggest endothelial cell injury was present in both groups. However, the intraalveolar edema results would seem to suggest a greater degree of injury to the alveolar-epithelial cell barrier of the $\mathrm{O}_{2}$-control group.

\section{DISCUSSION}

Hyperoxia upsets the normal cellular oxidant-antioxidant defense equilibrium by producing marked increases in $\mathrm{O}_{2}$ free radical production (25). The newborn animal's superior ability to resist $\mathrm{O}_{2}$-induced lung damage (and lethality) compared with adult animals appears to be at least partly related to the newborn's ability to increase its basal AOE activity levels in response to more than $95 \% \mathrm{O}_{2}$ hyperoxia, a biochemical response adult animals do not demonstrate (26-29). We had previously shown that after prenatal TRH treatment, despite lower baseline lung AOE activity levels, the TRH newborn rats were able to increase their baseline AOE activities markedly in response to hyperoxia (3). Unexpectedly, however, TRH offspring were found to have comparatively poorer survival in hyperoxia with increased indices of $\mathrm{O}_{2}$ radical-induced lung damage compared with control newborns (4). Because the maturation of the rat hypothalamicpituitary axis normally occurs relatively late in the neonatal period (30-32), the detrimental effects of TRH treatment on $\mathrm{O}_{2}$ tolerance during the first $2 \mathrm{wk}$ of life may have been related to a relative hyperthyroid state in the TRH-offspring compared with a relative hypothyroid state in control neonatal rats (with immature pituitary-hypothalamic function) (33). Significantly elevated $T_{3}$ and $T_{4}$ serum levels were in fact found in the 10-d-old prenatally TRH-treated offspring versus control 10-d-old rat pups (4). We speculate that this relative hyperthyroidism in TRH offspring may have enhanced basal metabolic rate, increased $\mathrm{O}_{2}$ consumption, and increased $\mathrm{O}_{2}$ radical production (34), which could have exceeded the detoxifying capacity of the antioxidant defense mechanisms and produced increased pulmonary $\mathrm{O}_{2}$ toxicity and reduced survival in hyperoxia. We undertook the present study to test the effect of inhibited endogenous thyroid hormone production (by PTU treatment) on the $\mathrm{O}_{2}$ tolerance of the newborn rat.

PTU is a thioamide derivative that is known to cross the placenta, inhibit thyroid hormone synthesis by blocking the incorporation of iodine, and also inhibit the peripheral deiodination of $T_{4}$ to $T_{3}(5)$. The serum hormone data (Table 2) reflect the effectiveness of maternal PTU treatment in the fetus and neonate when it is administered in the maternal rat's water source. Multiple investigations $(6,35)$ have recently reported that PTU, in addition to its antithyroid properties, has the ability to protect membrane lipids from peroxidative directly changes, the potential to scavenge free radicals directly (36), diminish $\mathrm{H}_{2} \mathrm{O}_{2}$ production $(37)$, reduce $\mathrm{O}_{2}$ radical production indirectly by 
decreasing the production of inflammatory mediators (38), and decrease $\mathrm{O}_{2}$ consumption and $\mathrm{O}_{2}$ radical production by its antithyroid actions (39). In fact, PTU is currently being used effectively to treat severe alcoholic liver disease (7), a hepatic hypermetabolic state with increases in hepatic uptake of $T_{4}$, increased hepatic $\mathrm{O}_{2}$ consumption, and excess superoxide radical production by hepatic microsomal fractions (8). Recently, patients treated with PTU have been found to have decreased serum levels of lipid peroxides, suggesting that PTU used clinically may scavenge $\mathrm{O}_{2}$ free radicals or may detoxify peroxyl radicals to prevent chain reaction lipid peroxidation (40).

The overall results of our newborn rat PTU treatment protocol represent the logical reversal of the results found previously in our prenatal TRH treatment study (4). In addition to the consistent and dramatically superior survival rate of the PTU-treated offspring in hyperoxia (compared with the poorer survival of TRH offspring), we found concomitant evidence of increased protection against $\mathrm{O}_{2}$ radical-induced lung damage in the MDA and DSPC/phospholipid data (Fig. 2), in the comparative intraalveolar edema results, and in the reduced inhibition of lung DNA (synthesis) during $\mathrm{O}_{2}$ exposure. The decrease in MDA may reflect not only a decrease in oxidative stress and lipid peroxidation but also possibly a decrease in the quantity of polyunsaturated lipids available for peroxidation. Hoch et al. (41), for example, reported that in rats made hypothyroid by thyroidectomy, their livers incorporated less linoleate $(18: 2)$ into unsaturated fatty acid (especially 20:4, arachidonic acid) and instead incorporated the label mainly into saturated fatty acids, suggesting that hypothyroidism may decrease the quantity of polyunsaturated lipids available for peroxidation. This finding is in agreement with the study of Fernandez et al. (8) in adult rats, in which $T_{3}$ treatment produced significant elevations of hepatic MDA levels versus untreated euthyroid rats. It is also conceivable to postulate that because PTU is soluble in a hydrophobic environment (6), the decrease in MDA may represent PTU's equilibration into surfactant-related phospholipids or membranes of the alveolar epithelium to act there as a chain-breaking antioxidant.

Our findings are in agreement with the study of Yam and Roberts (42) in adult rats, in which they reported a decrease in hyperoxic lethality and pulmonary edema after pretreatment with PTU. However, they also reported a significant increase in baseline pulmonary AOE activities with PTU treatment. Chen et al. (43), in rat pups prenatally treated with thyroid hormone, demonstrated a significant inhibition of the normal elevations in baseline AOE activity in the late gestational fetal lung caused by a direct negative regulation of $\mathrm{AOE}$ gene expression at the transcriptional level. Our comparative AOE levels at $5 \mathrm{~d}$ of life were not different between the PTU and control pups (Table 3), which is consistent with our previous work illustrating no difference in AOE activities at birth after thyroid inhibition (by PTU) when compared with control newborn rats (44). We were also unable to find the decrease in lung tissue cyanide anion-resistant $\mathrm{O}_{2}$ consumption and $\mathrm{O}_{2}$ radical formation that we anticipated in our PTU-treated animals, suggesting that either our (indirect) method was not sensitive enough to detect small but meaningful changes in $\mathrm{O}_{2}$ radical formation with PTU treatment or that PTU by its antioxidant action fosters the enhanced removal of free radicals in the neonatal lung without affecting $\mathrm{O}_{2}$ free radical production per se.

Whether PTU's marked protective effect against $\mathrm{O}_{2}$ toxicity in the newborn rat stems from its antithyroid properties and its effect on $\mathrm{O}_{2}$ metabolism or its direct antioxidant properties requires further exploration. It is conceivable that PTU treatment could protect the lungs of premature infants from the acute and chronic toxic damage associated with required $\mathrm{O}_{2}$ administration.

\section{REFERENCES}

1. Freeman BA, Crapo JD 1981 Hyperoxia increases oxygen radical production in rat lungs and lung mitochondria. J Biol Chem 256:10986-10992

2. Sosenko IRS, Frank L 1987 Thyroid hormone depresses antioxidant enzyme maturation in fetal rat lung. Am J Physiol 253:R592-R598

3. Rodriguez MP, Sosenko IRS. Antigua MC, Frank L 1991 Prenatal hormone treatment with thyrotropin releasing hormone and with thyrotropin releasing hormone plus dexamethasone delays antioxidant enzyme maturation but does not inhibit a protective antioxidant enzyme response to hyperoxia in newborn rat lung. Pediatr Res 30:522-527

4. Rodriguez-Pierce M, Sosenko IRS, Frank L 1992 Prenatal thyroid releasing hormone and thyroid releasing hormone plus dexamethasone lessen the survival of newborn rats during prolonged high $\mathrm{O} 2$ exposure. Pediatr Res 32:407-411

5. Wilson JD. Foster DW 1985 Neuroendocrinology. In: Williams RH (ed) Textbook of Endocrinology. WB Saunders, Philadelphia, pp 510-514

6. Hicks M, Wong LS, Day RO 1992 Antioxidant activity of propylthiouracil. Biochem Pharmacol 43:439-444

7. Orego H, Blake JE, Blendis LM, Compton KV, Israel Y 1987 Long-term treatment of alcoholic liver disease with propylthiouracil. N Engl J Med 317:1421-1427

8. Fernandez V, Barrientos X, Kipreos K, Valenzuela A, Videla LA 1985 Superoxide radical generation, NADPH oxidase activity, and cytochrome P-450 content of rat liver microsomal fractions in an experimental hyperthyroid state: relation to lipid peroxidation. Endocrinology 117:496-501

9. Cooper DS, Kieffier JD, Halpern R, Saxe V, Mover H, Maloof F, Ridgway EC 1983 Propylthiouracil (PTU) pharmacology in the rat. II. Effect of PTU on thyroid function. Endocrinology 113:921-928

10. Buege JA, Aust SD 1978 Microsomal lipid peroxidation. Methods Enzymol 52:302-310

11. Tappel AL 1980 Measurement of and protection from in vivo lipid peroxidation. In: Pryor W (ed) Free Radical in Biology. Vol 4. Academic Press, New York, pp 1-47

12. Freeman BA, Topolosky MK. Crapo JD 1982 Hyperoxia increases oxygen radical production in rat lung homogenates. Arch Biochem Biophys 216:477-484

13. McCord JM, Fridovich 11969 Superoxide dismutase: an enzymatic function for erythrocuprein (hemocuprein). J Biol Chem 244:6049-6055

14. Holmes RS, Masters CJ 1970 Epigenetic interconversions of the multiple forms of mouse liver catalase. FEBS Lett 11:45-48

15. Paglia DE, Valentine WN 1967 Studies on the quantitative and qualitative characterization of erythrocyte glutathione peroxidase. J Lab Clin Med 70:158-159

16. Schacterle GR, Pollack RL 1973 A simplified method for the quantitative assay of small amounts of protein in biological materials. Anal Biochem 51:654-655

17. Richards GM 1974 Modification of the diphenylamine reaction giving increased sensitivity and simplicity in the estimation of DNA. Anal Biochem 57:369-376

18. Bligh EF. Dyer WJ 1959 A rapid method of total lipid extraction and purification. Can J Biochem Physiol 37:911-917

19. Morrison WR $1964 \mathrm{~A}$ fast simple and reliable method for the microdetermination of phosphorous in biological materials. Anal Biochem 11:218-224

20. Mason RJ, Nellenbogen J. Clements JA 1976 Isolation of disaturated phosphatidylcholine with osmium tetroxide. J Lipid Res 17:281-284

21. Weibel ER. Staubli W, Gongi HR, Hess FA 1969 Correlated morphometric and biochemical studies on the liver cell. I. Morphometric model. Stereological methods and normal morphometric data for rat liver. J Cell Biol 42:6991

22. Thurlbeck WM, Galaugher W, Mather J 1981 Adaptive response to pneumonectomy in puppies. Thorax 36:414-427

23. Weibel ER 1963 Morphometry of the Human Lung. Academic Press, New York, pp 51-73

24. Steel RGD, Torrie JH 1960 Principles and Procedures of Statistics. McGraw Hill, New York, pp 366-387

25. Zweir JL, Duke SS, Kuppusamy P, Sylvester JT, Gabrielson EW 1989 Electron paramagnetic resonance evidence that cellular oxygen toxicity is caused by generation of superoxide and hydroxyl free radical. FEBS Lett 252:12-16

26. Frank L 1991 Developmental aspects of experimenta! pulmonary oxygen toxicity. Free Radic Biol Med 11:463-494

27. Fanburg BL, Denke SM 1989 Hyperoxia: toxicity and adaptation. In: Massaro D (ed) Lung Cell Biology, Vol 41 [series: Lung Biology in Health and Disease]. Marcel-Dekker, New York, pp 1199-1226

28. Frank L, Sosenko IRS 1991 Failure of premature rabbits to increase antioxidant enzymes during hyperoxic exposure: increased susceptibility to pulmonary oxygen toxicity compared with term rabbits. Pediatr Res 29:292-296

29. Roberts RJ, Frank L 1984 Developmental consequences of oxygen toxicity. In: Kacew S, Reasor M (eds) Toxicology and the Newborn. Elsevier Scientific, New York, pp 141-171

30. Dussault JH, Labrie F 1975 Development of the hypothalamic-pituitarythyroid axis in the neonatal rat. Endocrinology 97:1321-1324

31. El-Zaheri MM, Vagenakis AG, Hinerfeld L, Emerson CH, Brauerman LE 1981 Maternal thyroid function is the major determinant of amniotic fluid 3,3',5-triiodothyronine in the rat. J Clin Invest 67:1126-1133

32. Schwartz H, Oppenheimer JH 1978 Ontogenesis of 3.5.3'-triiodothyronine. Endocrinology 103:943-948

33. Beltz AD, Reineke EP 1968 Thyroid secretion rate in the neonatal rat. Gen Comp Endocrinol 10:103-108

34. Barker SB, Klitgard HM 1952 Metabolism of tissue excised from thyroxineinjected rats. Am J Physiol 170:81-86

35. Paller MS, Sikora JJ 1985 Hypothyroidism protects against free radical damage 
in ischemic acute renal failure. Kidney Int 29:1162-1166

36. Wilson R, McKillop JH, Travers M. Smith J, Smith E, Thomson JA 1990 The effects of antithyroid drugs on intercellular mediators. Acta Endocrinol 122:605-609

37. Heufelder AE, Wenzel BE, Bahn RS 1992 Methimazole and propylthiouracil inhibit the oxygen free radical-induced expression of a 72 kilodalton heat shock protein in graves retroocular fibroblasts. J Clin Endocrinol Metab 74:737-742

38. Weetman AP, Tendon N, Morgan BP 1992 Antithyroid drugs and release of inflammatory mediators by complement-attacked thyroid cells. Lancet 340:633-636

39. McAllister RM, Ogilvie RW, Terjung RL 199! Functional and metabolic consequences of skeletal muscle remodeling in hypothyroidism. Am J Physiol
260:E272-E279

40. Videla LA, Sir T, Wolff C 1988 Increased lipid peroxidation in hyperthyroid patients: suppression by propylthiouracil treatment. Free Radic Res Commun $5: 1-10$

41. Hoch FL, Subramanian C, Dhopeshwarkar GA, Mead JF 1981 Thyroid contro over biomembranes: VI. Lipids in liver mitochondria and microsomes of hypothyroid rats. Lipids 16:328-335

42. Yam J, Roberts RJ 1978 Pharmacological alteration of oxygen-induced lung toxicity. Toxicol Appl Pharmacol 47:367-375

43. Chen Y, Whitney PL, Frank L 1993 Negative regulation of antioxidant enzyme gene expression in the developing fetal rat lung by prenatal hormonal treatments. Pediatr Res 33:171-176

44. Sosenko IRS, Frank L 1989 Thyroid inhibition and developmental increases in fetal rat lung antioxidant enzymes. Am J Physiol 257:L94-L99 